\title{
PRÁTICAS EDUCATIVAS, ESTILOS PARENTAIS E ABUSO FÍSICO NO CONTEXTO FAMILIAR
}

\author{
Alessandra Marques Cecconello* \\ Clarissa De Antoni" \\ Sílvia Helena Koller"
}

\begin{abstract}
RESUMO. Este artigo apresenta uma revisão de literatura sobre práticas educativas e estilos parentais no contexto familiar, com o objetivo de analisá-los como fatores potenciais de proteção ou de risco para o abuso físico, sob o enfoque ecológico do desenvolvimento humano. São discutidos vários indicadores nas esferas familiar, pessoal e social, tais como: características individuais, experiência dos pais em suas famílias de origem, rede de apoio social e eventos estressantes no ciclo vital. A compreensão destes aspectos permite subsidiar a elaboração de programas de intervenção e prevenção de casos de abuso físico na família, além de promover novas pesquisas.
\end{abstract}

Palavras-chave: Práticas educativas, estilos parentais, abuso físico.

\section{SOCIALIZATION PRACTICES, PARENTING STYLES AND PHYSICAL ABUSE IN FAMILIAR CONTEXT}

\begin{abstract}
This paper presents a literature review about socialization practices and parental styles in familiar context, aiming to analyze them as risk and protective potential factors for physical abuse, based on ecological perspective of human development. Several factors are analyzed at familiar, personal and social perspectives, such as individual characteristics, parents' experience in their families of origin, social support network, and stressful life events. The comprehension of these factors may subsidize both intervention programs and prevention of cases of physical abuse in families, and also to encourage new research.
\end{abstract}

Key words: socialization practices, parental styles, physical abuse.

As relações intrafamiliares vêm sofrendo mudanças nas últimas décadas. Alguns anos atrás, comportamentos até então compreendidos como culturalmente aceitáveis e esperados, como a utilização de força física na educação das crianças por parte dos pais ou cuidadores, atualmente são criticados e coibidos pelos direitos constitucionais (ver, por exemplo, Estatuto da Criança e do Adolescente, 1990). No entanto, o processo de mudança que permite a conscientização sobre os danos causados pela punição física é lento. Ainda persiste, por exemplo, a punição no contexto familiar, justificada, muitas vezes, como uma prática educativa. Este artigo apresenta uma revisão da literatura sobre as práticas educativas, os estilos parentais e o abuso físico no contexto familiar, com o objetivo de analisar tais práticas e estilos parentais como fatores potenciais de proteção ou de risco para o abuso físico, através da Teoria dos Sistemas Ecológicos (Bronfenbrenner, 1979/1996).

\footnotetext{
Psicóloga, Mestre e Doutora em Psicologia do Desenvolvimento, coordenadora do Núcleo de Estudos e Capacitação em Desenvolvimento Humano (NECADEH/CEP-Rua/UFRGS) e da equipe de pesquisa sobre Resiliência Familiar. Apoio CNPq. Docente da Faculdade Cenecista de Ciências e Letras de Osório (FACOS).

\# Psicóloga, Especialista em Psicologia Social, Mestre e Doutoranda em Psicologia do Desenvolvimento, coordenadora do Núcleo de Estudos em Desenvolvimento Comunitário e Cidadania (NEDECC/CEP-Rua/UFRGS) e da equipe de pesquisa sobre Violência Intrafamiliar. Apoio CAPES.

Il Psicóloga, Doutora em Educação, Pesquisadora do CNPq e Professora do Curso de Pós-Graduação em Psicologia do Desenvolvimento, Universidade Federal do Rio Grande do Sul. Coordenadora do Centro de Estudos Psicológicos sobre Meninos e Meninas de Rua (CEP-Rua/UFRGS).

Endereço para correspondência: CEP-RUA/UFRGS, Instituto de Psicologia, Rua Ramiro Barcelos, 2600/104, CEP 90035.003, Porto Alegre-RS. E-mails: marquesa@terra.com.br; clarissa@yahoo.com.br
} 
De acordo com Bronfenbrenner (1979/1996), a família é caracterizada como o primeiro ambiente do qual a criança participa ativamente, interagindo através de relações face-a-face. Inicialmente, estas interações ocorrem de forma diádica, como, por exemplo, pela relação da mãe com a criança. Aos poucos, as relações vão se expandindo dentro do grupo familiar, formando, dentro deste sistema, vários subsistemas, como a relação pai-criança e a relação entre irmãos. A família com a qual a criança interage diretamente é denominada de microssistema. Idealmente, o microssistema familiar é a maior fonte de segurança, proteção, afeto, bem-estar e apoio para a criança. Nele a criança exercita papéis e experimenta situações, sentimentos e atividades. Dentro dele, a criança desenvolve o senso de permanência e o de estabilidade. $\mathrm{O}$ senso de permanência está relacionado com a percepção de que elementos centrais da experiência de vida são estáveis e se mantêm organizados, através de rotinas e rituais familiares. $\mathrm{O}$ senso de estabilidade é fornecido através do sentimento de segurança dos pais aos filhos, de que não haverá rupturas ou rompimentos, mesmo diante de situações de estresse (De Antoni, Medeiros, Hoppe \& Koller, 1999). A garantia de permanência e estabilidade faz a família funcionar como um sistema integrado, cujo objetivo principal é o de promover o bem-estar de seus membros.

Bronfenbrenner (1979/1996) destaca três características que se estabelecem nas relações dentro da família: a reciprocidade, o equilíbrio de poder e o afeto. Em qualquer relação, o que uma pessoa faz influencia a outra, e vice-versa, caracterizando a reciprocidade. Contudo, mesmo que as relações sejam assim caracterizadas, um dos participantes pode ser mais influente do que o outro. A extensão em que, numa relação, $\underline{A}$ é mais influente que $\underline{B}$ e esta condição é saudável e confortavelmente aceita é definida como equilíbrio de poder. Para uma criança pequena, a participação em uma díade oferece a oportunidade de aprender a lidar com relações de poder. Uma situação ótima para o desenvolvimento é aquela em que o equilíbrio de poder gradualmente se altera em favor da pessoa em desenvolvimento, promovendo o desenvolvimento da autonomia. Além de reciprocidade e equilíbrio de poder, existe outra característica que desempenha um papel fundamental para o desenvolvimento: o afeto. Quanto mais positivas e calorosas forem as relações de uma díade, maior a probabilidade de ocorrerem processos evolutivos de forma adaptada.

Várias pesquisas em Psicologia têm enfatizado a importância da interação parental e das práticas educativas utilizadas pelos pais sobre o desenvolvimento de crianças e adolescentes (Baumrind, 1966, 1997; Darling \& Steinberg, 1993; Maccoby \& Martin, 1983). A literatura sobre o tema permite identificar duas dimensões distintas na interação de pais e filhos: as práticas educativas e os estilos parentais. As práticas educativas referem-se às estratégias utilizadas pelos pais para atingir objetivos específicos em diferentes domínios (acadêmico, social, afetivo) sob determinadas circunstâncias e contextos (Hart, Nelson, Robinson, Olsen \& McNeilly-Choque, 1998). O uso de explicações, de punições ou de recompensas constitui exemplo dessas práticas. $\mathrm{O}$ estilo parental refere-se ao padrão global de características da interação dos pais com os filhos em diversas situações, que geram um clima emocional (Darling \& Steinberg, 1993). A expressão do comportamento parental pode apresentar afetividade, responsividade e autoridade.

Até mesmo ao utilizar uma medida restritiva no comportamento de uma criança um pai ou uma mãe podem demonstrar afeto e cuidado e estimular o exercício da autonomia responsável. Uma medida punitiva, no entanto, revela-se sempre pela imposição, caracterizando um estilo parental autoritário. A utilização deste tipo de punição, especialmente quando se trata de uma punição física, pretendendo ser uma prática disciplinar, tem sido descrita na literatura como prejudicial ao desenvolvimento de crianças e adolescentes (Hart, Ladd \& Burleson, 1990; Hart, Nelson, Robinson, Olsen \& McNeilly-Choque , 1998; Hoffman, 1960, 1975). Para os teóricos do assunto, tal prática está baseada no uso abusivo do poder que os pais têm sobre os filhos. Contraria, portanto, a proposição da Teoria dos Sistemas Ecológicos, pela qual a família deveria ser, primordialmente, um sistema no qual as relações são recíprocas e com equilíbrio de poder.

Hoffman (1960) define o poder como o potencial que uma pessoa tem para compelir a outra a agir de maneira contrária à sua própria vontade. A relação entre pais e filhos ilustra uma típica situação na qual existe uma concentração de poder na figura dos pais. Existem, no entanto, duas maneiras pelas quais os pais podem utilizar este poder para alterar o comportamento dos filhos: a primeira, através de uma disciplina indutiva, que objetiva uma modificação voluntária no comportamento da criança; e a segunda, através de técnicas que reforçam e reafirmam o poder parental, como práticas coercitivas. Devido à sua privilegiada posição de poder, os pais podem, livremente, escolher entre as técnicas disponíveis para monitorar o comportamento dos filhos (Hoffman, 1960). 
A disciplina indutiva envolve práticas educativas que comunicam à criança o desejo dos pais de que ela modifique seu comportamento, induzindo-a a obedecer-lhes (Hoffman, 1975). Esta estratégia disciplinar caracteriza-se por direcionar a atenção da criança para as consequiências de seu comportamento às outras pessoas e para as demandas lógicas da situação, ao invés das consequiências punitivas para ela mesma. Práticas deste tipo envolvem explicações sobre as conseqüências do comportamento da criança, explicações sobre regras, princípios, valores, advertências morais, apelos ao orgulho da criança e ao amor que ela sente pelos pais, explicações sobre as possíveis implicações maléficas ou dolorosas das ações da criança para os outros e para si mesma e sobre o seu relacionamento com as outras pessoas (Grusec \& Lytton, 1988).

A disciplina coercitiva, por outro lado, caracteriza-se por práticas que utilizam a aplicação direta da força e do poder dos pais (Hoffman, 1975). Tais práticas incluem punição física e privação de privilégios ou ameaças, compelindo a criança a adequar seu comportamento às reações punitivas dos pais. Estas práticas podem provocar emoções intensas, como hostilidade, medo e ansiedade, interferindo na capacidade da criança para ajustar seu comportamento à situação. As estratégias coercitivas provocam o controle do comportamento baseado na ameaça de sanções externas e intensificam a percepção de valores e do padrão de ação moral como externos, enquanto as estratégias indutivas favorecem a internalização moral (Hoffman, 1975).

De acordo com Grusec e Lytton (1988), práticas coercitivas, como a punição, condicionam a inibição daqueles comportamentos infantis reprimidos pelos pais. As sanções punitivas tendem a eliciar sentimentos negativos nas crianças, inibindo a produção dos comportamentos, devido à ansiedade gerada por ela mesma ou por sua ameaça. Os autores distinguem duas formas de punição: a coerção e a ameaça de rompimento do vínculo afetivo entre a criança e os pais. Esta segunda forma de punição perturba o sentimento de segurança da criança com relação aos sentimentos parentais, gerando ansiedade. A utilização indiscriminada de ambas as formas de punição traz inúmeros prejuízos ao desenvolvimento psicológico da criança. Crianças cujas mães utilizam práticas disciplinares coercitivas tendem a usar métodos coercitivos na resolução de conflito com seus pares, sendo, por conseguinte, menos aceitas por eles (Hart, Ladd \& Burleson, 1990). Da mesma forma, a coerção parental, a falta de responsividade e o controle excessivo estão relacionados com várias formas de agressão infantil e comportamentos de vitimização (Hart, Nelson, Robinson, Olsen \& McNeilly-Choque, 1998).

Uma medida restritiva, como a aplicação de uma punição, pode ser utilizada como decorrência natural de um comportamento inapropriado, devendo vir acompanhada de explicações lógicas e adequadas à situação. A percepção de estar sendo cuidada pode minimizar os sentimentos negativos na criança, reduzindo a probabilidade de resultados indesejados no seu desenvolvimento (Grusec \& Lytton, 1988). O uso ocasional de disciplina coercitiva por pais que utilizam, freqüentemente, disciplina indutiva, em certas circunstâncias não prejudica o desenvolvimento da criança, evidentemente, isto não se aplica à punição física (Hoffman, 1960, 1975). As estratégias coercitivas podem minimizar este caráter quando se tornam qualificadas, ou seja, quando existe uma explicação para justificar ou legitimar a solicitação da mudança de comportamento, baseada não em motivos centrados no poder dos pais, mas, por exemplo, no bem-estar da criança ou em normas sociais que esta entenda e também valorize (Hoffman, 1960).

A utilização inadequada do poder dos pais, presente na disciplina coercitiva, também pode ser observada em outros aspectos da interação parental. $\mathrm{O}$ controle excessivo do comportamento dos filhos pelos pais ilustra um desequilíbrio de poder na relação, o qual impede o desenvolvimento de características e habilidades importantes, como auto-estima e autonomia. O controle é uma das dimensões presentes nas tipologias de estilos parentais, conforme inicialmente proposto por Baumrind $(1966,1971) \mathrm{em}$ seu modelo. Suas pesquisas focalizaram a influência da variação normal da autoridade parental sobre o desenvolvimento infantil, reformulando a antiga visão de controle, até então definido em termos de rigidez e punição física (Darling \& Steinberg, 1993). Na sua concepção, o controle está relacionado com exigências e expectativas de maturidade impostas pelos pais, através de confrontações diretas, supervisão e disciplina consistente (Baumrind, 1997). A variação no nível do controle, aliada a outros aspectos da interação parental, como comunicação e afeto, produz três diferentes estilos parentais: o autoritativo ${ }^{1}$, o autoritário e o permissivo.

O modelo de estilos parentais de Baumrind (1966, 1971) foi, posteriormente, reformulado por Maccoby e Martin (1983), que propuseram duas dimensões

Devido à falta de consenso entre os pesquisadores para a tradução do termo authoritative, optou-se por manter a denominação utilizada nos estudos brasileiros de Pacheco, Teixeira e Gomes (1999) e Alvarenga (2000). 
ortogonais - exigência e responsividade - cuja combinação resulta em quatro estilos parentais. A exigência refere-se aos comportamentos parentais que requerem supervisão e disciplina. A responsividade refere-se aos comportamentos de apoio e aquiescência, que favorecem a individualidade e a auto-afirmação dos filhos. Os quatro estilos parentais emergentes deste modelo são: o autoritativo, o autoritário, o indulgente e o negligente. A diferença básica entre a tipologia proposta por Baumrind e a proposta por Maccoby e Martin reside na separação do estilo permissivo em dois: o indulgente e o negligente. Esta diferenciação permitiu distinguir, nas famílias que fazem poucas demandas de controle, uma variação no seu nível de responsividade.

O estilo autoritativo resulta da combinação entre exigência e responsividade em altos níveis. Pais autoritativos estabelecem regras para o comportamento de seus filhos que são consistentemente enfatizadas. Eles monitoram a sua conduta, corrigindo atitudes negativas e gratificando atitudes positivas. A disciplina é imposta de forma indutiva e a comunicação entre pais e filhos é clara e aberta, baseada no respeito mútuo. São pais que têm altas expectativas em relação ao comportamento dos filhos em termos de responsabilidade e maturidade. Além disso, são afetuosos na interação com eles, responsivos às suas necessidades e, freqüentemente, solicitam sua opinião quando conveniente, encorajando a tomada de decisões e proporcionando oportunidades para o desenvolvimento de suas habilidades (Baumrind, 1966; Glasgow, Dornbusch, Troyler, Steinberg \& Ritter, 1997).

O estilo autoritário resulta da combinação entre altos níveis de controle e baixa responsividade. Pais autoritários são rígidos e autocráticos. Eles impõem altos níveis de exigência, estabelecendo regras estritas, independentemente de qualquer participação da criança. Tendem a enfatizar a obediência através do respeito à autoridade e à ordem. Freqüentemente utilizam a punição como forma de controle do comportamento. Não valorizam o diálogo e a autonomia, reagindo com rejeição e baixa responsividade aos questionamentos e opiniões da criança (Baumrind, 1966; Glasgow, Dornbusch, Troyler, Steinberg \& Ritter, 1997).

O estilo indulgente resulta da combinação entre baixo controle e alta responsividade. Pais indulgentes, em oposição aos autoritários, não estabelecem regras nem limites para a criança, estabelecendo poucas demandas de responsabilidade e maturidade. São excessivamente tolerantes, permitindo que a criança monitore seu próprio comportamento. São afetivos, comunicativos e receptivos com seus filhos, tendendo a satisfazer qualquer demanda que a criança apresente (Baumrind, 1966; Glasgow, Dornbusch, Troyler, Steinberg \& Ritter, 1997).

$O$ estilo negligente resulta da combinação entre controle e responsividade em baixos níveis. Pais negligentes não são nem afetivos nem exigentes. Demonstram pouco envolvimento com a tarefa de socialização da criança, não monitorando seu comportamento. Tendem a manter seus filhos a distância, respondendo somente às suas necessidades básicas. Enquanto os pais indulgentes estão envolvidos com seus filhos, os pais negligentes estão, freqüentemente, centrados em seus próprios interesses (Glasgow, Dornbusch, Troyler, Steinberg \& Ritter, 1997).

Várias pesquisas destacam a influência positiva do estilo autoritativo sobre o desenvolvimento psicológico de crianças e adolescentes. Este estilo está relacionado com competência social, assertividade e comportamento independente de crianças (Baumrind, 1966). Em adolescentes, encontra-se associado com melhores níveis de adaptação psicológica, competência social, auto-estima, desempenho acadêmico, autoconfiança e menores níveis de problemas de comportamento, ansiedade e depressão (Baumrind, 1991; Lamborn, Mounts, Steinberg \& Dornbusch, 1991; Steinberg, Lamborn, Darling, Mounts \& Dornbusch, 1994; Steinberg, Mounts, Lamborn \& Dornbusch, 1991). Por outro lado, os estilos autoritário, indulgente e negligente parecem estar relacionados com uma maior incidência de resultados negativos no desenvolvimento, como problemas de comportamento, abuso de substâncias, fracasso escolar e baixa auto-estima (Lamborn e cols., 1991; Steinberg e cols., 1994).

Como é possível observar, as relações de poder dentro da família influenciam amplamente os estilos parentais e as práticas educativas utilizadas com os filhos. A falta extrema de afeto ou a rejeição gera conseqüências negativas para o desenvolvimento. Se, na relação que se estabelece entre os pais e a criança, o afeto, a reciprocidade e o equilíbrio de poder não estão presentes, pode ocorrer prejuízo ao desenvolvimento da criança, comprometendo as relações posteriores que ela virá a estabelecer com outras pessoas (Bronfenbrenner, 1979/1996).

Neste sentido, a utilização da punição física como uma prática disciplinar não apenas reafirma o poder dos pais sobre os filhos, favorecendo o seu desequilíbrio, mas também prejudica a relação de reciprocidade e de afeto entre eles. A punição corporal, conforme mencionado anteriormente, elicia 
sentimentos negativos por parte da criança, elevando o nível de ansiedade devido ao medo da punição ou de sua ameaça. Pires (1999) afirma que a punição gera uma confusão de sentimentos, ocasionando a falta de discernimento entre amor, dor, ódio e submissão. Desta forma, prejudica a capacidade da criança para adequar seu comportamento às exigências dos pais, diminuindo, assim, a reciprocidade. Além de não ser uma prática eficaz, a utilização indiscriminada de punição física acarreta um comportamento abusivo, trazendo inúmeras conseqüências negativas para a criança. O abuso físico viola um dos direitos básicos do ser humano - ter domínio sobre seu próprio corpo.

\section{O ABUSO FÍSICO NA FAMÍLIA}

O abuso físico intrafamiliar é multidirecional, pois poderá ocorrer entre quaisquer de seus membros, por exemplo: pais e filho(a), irmãos, casal, entre outros. No entanto, especificamente neste texto, o abuso físico será abordado com relação ao uso de força física contra a criança e o adolescente por parte do cuidador, seja este o pai ou a mãe - biológicos ou adotivos - seja outro parente, os quais deveriam zelar pelo bem-estar da pessoa sob sua tutela. O abuso físico é mais facilmente identificável quando há lesões orgânicas diagnosticáveis, como cutâneas e ósseas, problemas neurológicos e oculares, etc. Estas lesões podem ser provocadas por ações de força contra a criança ou adolescente, que envolvem, por exemplo, surras, queimaduras, mordidas, tapas, socos ou lançamento de objetos contra o corpo deles (Farinatti, Biazus \& Leite, 1993; Garbarino \& Eckenrode, 1997; Oates, Ryan \& Booth, 2000).

O primeiro relato médico sobre abuso físico infantil ocorreu na França, em 1868, quando Ambrose Tardieu, patologista forense, publicou um estudo com uma amostra de trinta e duas crianças que tinham sido "sacudidas" até a morte. Em 1946, o radiologista americano John Caffey descreveu a síndrome, ocorrida em seis crianças, que continha os seguintes sintomas: hematomas e fraturas múltiplas ao longo dos ossos, contusões e hemorragia na retina, desnutrição e atraso no desenvolvimento. Além da descrição dos sintomas, Caffey sugeriu que esta síndrome poderia ter sido causada por um trauma provocado, "talvez", por negligência dos pais. No entanto, somente em 1962, Kempe e cols corajosamente relataram, através da publicação de um artigo, que os traumas eram provocados pelo abuso físico dos pais. Com o intuito de demonstrar a severidade dos sintomas e a necessidade da conscientização sobre o perigo dos maus tratos que os pais ou cuidadores poderiam causar à criança, a denominaram de "síndrome do bebê sacudido". A partir daí, iniciaram-se estudos sistemáticos sobre o tema (Oates, Ryan \& Booth, 2000). Atualmente, esta síndrome é descrita quando a criança é repetidamente sacudida pelos pais que reagem ao seu choro contínuo, e acomete, principalmente, a lactentes menores de seis meses. Os sintomas do bebê sacudido são variados, incluindo apatia, crises convulsivas, irritabilidade e falta de apetite (Pires, 1999).

Geralmente, o abuso físico a bebês e crianças ocorre no lar. As vítimas, muitas vezes, não relatam o fato por não saberem se expressar verbalmente ou por temerem a reincidência do abuso. Quando são adolescentes, no entanto, tendem a não suportar a agressão, e por apresentarem mais condições físicas e emocionais, confrontam a situação ou fogem dela (De Antoni, Mesquita \& Koller, 1998). Os abusadores costumam justificar o episódio como um acidente, utilizando explicações vagas e incoerentes. A falta de informações fidedignas dificulta um diagnóstico preciso. Todavia, a definição clara do quadro, muitas vezes, se expressa pelas repetidas internações hospitalares de crianças e adolescentes com os mesmos sintomas (Oates, Ryan \& Booth, 2000; Pires, 1999).

A pesquisa realizada por Kristensen, Oliveira e Flores (1999) sobre a incidência deste tipo de violência em relação à criança revela a existência do abuso físico no contexto familiar em mais da metade dos casos registrados, mais precisamente, em cerca de $55,3 \%$ deles. Sabe-se que o abuso físico não é registrado quando há concomitância de abuso sexual. Portanto, a sua incidência deve ser maior do que a notificada. Embora haja maior freqüência de ocorrência, o abuso físico no microssistema familiar é menos criticado do que o abuso sexual. Valores existentes no macrossistema - conjunto de ideologias, crenças e culturas existentes em determinado contexto - justificam este fenômeno como a aceitação e a permissão da punição corporal. As causas do abuso físico contra a criança e o adolescente são multifatoriais e devem ser compreendidas ecologicamente, através das perspectivas social, familiar e pessoal (Garbarino \& Eckenrode, 1997; Pelcovitz e cols., 2000; Sepmitus-Berger, 1999).

$\mathrm{Na}$ perspectiva social, o risco de abuso físico intrafamiliar está relacionado ao isolamento social, à falta de uma rede de apoio social e afetivo e aos eventos de vida estressantes, como dificuldades financeiras e desemprego. O estudo de Crouch, Milner e Thomsen (2001) e o de Wilson e Whipple (2001) confirmam a associação entre o risco de abuso físico e 
a percepção da ausência de uma rede de apoio. Pais abusivos recebem significativamente menos apoio emocional e instrumental de amigos ou parentes, pessoas estas que poderiam impedir as suas atitudes agressivas (Coohey, 2000). A transição de papéis da criança por vários ambientes pode auxiliá-la a criar uma rede de apoio social e afetivo fundamental para sua proteção. A riqueza do mesossistema, isto é, do conjunto de microssistemas no qual a pessoa transita, é mensurada através da quantidade e qualidade das suas conexões. Quanto mais coesas a família e a escola, por exemplo, estiverem em relação a valores e estilos de comportamento positivos, melhor a criança poderá desenvolver suas capacidades. $\mathrm{O}$ risco para o abuso está nas informações e comportamentos contraditórios encontrados nos diferentes microssistemas. A criança poderá tornar-se confusa em relação ao tipo de comportamento esperado em determinada situação. Isto pode ocorrer, por exemplo, quando é estimulada na escola a tomar decisões e, em casa, não pode, sequer, opinar. A escassez de ambientes e a falta de conexão entre eles também poderão ser fatores de risco, pois o mesossistema poderá não se configurar como uma rede (Garbarino \& Eckenrode, 1997).

Da mesma forma, o impacto dos eventos de vida estressantes é considerado um fator de risco para situações de abuso e maus tratos. A dificuldade financeira, o desemprego e a dificuldade em ingressar no mercado de trabalho reduzem o envolvimento parental e aumentam a probabilidade de utilização de disciplina severa (Simons, Lorenz, Conger \& Wu, 1992; Steinberg, Catalano \& Dooley, 1981). Portanto, o exossistema - ambiente do qual a criança não participa ativamente, mas sofre influência - pode propiciar condições para a a ocorrência do abuso, ao não controlar o nível de desemprego, de insegurança e de estresse no trabalho, entre outros. Sendo assim, a presença ou ausência de decisões sociopolíticas e econômicas salutares em um governo podem gerar condições que facilitam ou dificultam a ocorrência de abuso no microssistema familiar. No macrossistema, existem fatores de risco que contribuem para a existência do abuso, como: a aceitação cultural da violência dos pais para com os filhos, principalmente da punição corporal, como citado anteriormente; a visão cultural de posse da criança, que deve obedecer indistintamente aos pais; a ausência de compromisso com os direitos da criança e da mulher; a violência na mídia, entre outros (Koller, 1999).

$\mathrm{Na}$ perspectiva familiar, o uso da força física contra crianças ou adolescentes por seus pais ou cuidadores revela uma crença nos valores autoritários e na asserção do poder dos pais sobre os filhos (Garbarino \& Eckenrode, 1997). O abuso físico é justificado e compreendido pelos membros familiares como uma prática disciplinar (De Antoni, 2000; Pires, 1999). O poder está concentrado permanentemente em um familiar, no caso, o abusador. Tal centralização de poder revela o desequilíbrio entre os membros da família (De Antoni, 2000; Garbarino \& Eckenrode, 1997; Kashani \& Allan, 1998). Estudos realizados com famílias com história de abuso físico mostram que pais abusivos tendem a desencadear menos situações de interação com seus filhos do que os pais não abusivos (Kashani \& Allan, 1998). Há pouco contato físico, pouca demonstração de carinho e intensa rejeição entre eles. Os pais e as crianças exibem mais comportamentos descritos como negativos e poucos comportamentos positivos. Segundo Pelcovitz e cols. (2000), os adolescentes vítimas de abuso percebem suas famílias como significativamente menos adaptadas e coesas, sendo seus pais considerados menos bondosos e mais rígidos. Além disso, tais adolescentes têm a percepção de afastamento emocional entre os pais e eles. A relação entre os pais abusadores e seus filhos apresenta-se marcada pela hostilidade e com ausência de estabilidade e reciprocidade (De Antoni \& Koller, 2000; Kashani \& Allan, 1998; Koller, 1999). Também nestas famílias foram encontrados altos níveis de conflito conjugal (Septimus-Berger, 1999).

$\mathrm{Na}$ pesquisa realizada por Dopke (1999) sobre eventos estressores parentais e o risco para o abuso físico, foi constatado que as mães vêem a recusa da criança a uma ordem materna e a manutenção desta recusa como um evento estressor nesta interação diádica. A criança recusa-se a agir em conformidade com o determinado pela mãe, apresentando comportamento não desejado, e ocasiona significativamente mais o uso de estratégias disciplinares coercitivas do que de estratégias disciplinares indutivas. No microssistema familiar, encontram-se, também, alguns fatores que podem predispor à violência, como: falta de comunicação e de confiança, a estrutura e a configuração familiar por exemplo, famílias uniparentais, maternidade na adolescência, ausência do pai (De Antoni, 2000; De Antoni \& Koller, 2000; Koller, 1999).

$\mathrm{Na}$ perspectiva pessoal, são citadas como causadoras do abuso físico as características ou transtornos de personalidade, tanto do abusador quanto do abusado, como impulsividade, agressividade, transtornos de humor, doença mental ou física e deficiência física, entre outros. Além disso, há o risco de maus tratos contra crianças ocasionado 
pela depressão pós-parto e pelo uso de drogas, incluindo bebidas alcoólicas. A capacidade cognitiva dos pais também pode dificultar o desempenho adequado do papel parental. Segundo Bolger, Thomas e Eckenrode (1997), as limitações cognitivas ou de julgamento podem levar os pais ou cuidadores a reagirem de forma violenta frente aos estágios de desenvolvimento esperados na criança (como, por exemplo, a imaturidade para o controle dos esfíncteres em bebês) ou evidenciar a incapacidade de identificar possíveis riscos no ambiente (como, por exemplo, permitir que a criança brinque com sacos plásticos ou fogo).

A experiência dos pais em suas famílias de origem também contribui para o aumento do risco de abuso (Simons \& Johnson, 1996). Segundo indicam alguns estudos, pais que receberam educação severa e/ou foram vítimas de maus tratos na infância apresentam maior risco para repetir esta experiência com seus próprios filhos (Belsky, 1980; Patterson \& Capaldi, 1991; Simons, Whitbeck, Conger \& Chyi-In, 1991).

Simons, Whitbeck, Conger e Chyi-In (1991) realizaram uma revisão da literatura sobre parentalidade severa, ou seja, utilização de punição como prática disciplinar principal e estilo parental autoritário. Os estudos encontrados revelam convergência, ao concluírem que o determinante mais significativo para a prática/criação abusiva é o fato de que pais severos vivenciaram punição quando crianças. Este achado confirma a existência do "ciclo de violência", ou seja, pessoas tratadas com severidade quando jovens, crescem utilizando prática similar com seus próprios filhos. Este ciclo de violência é explicado pela Teoria da Aprendizagem Social através dos processos de modelação ou de reforço, que podem desencadear o efeito da transmissão intergeracional. Bandura (1979) conceitua modelação como uma aprendizagem através da observação e do reforço, como um estímulo constante a um determinado comportamento. A severidade dos pais em uma geração pode influenciar diretamente a parentalidade da próxima geração, através do efeito de modelação simples, ou pode ser transmitida indiretamente, através do estilo de relacionamento interpessoal ou das crenças parentais. As medidas coercitivas fazem parte do processo de parentalidade de uma pessoa que conviveu em um ambiente onde havia um tratamento severo, quando criança. Ela aprende que esta é uma forma usual de relacionar-se. De modo geral, as pessoas tendem a compreender superficialmente as práticas parentais rotineiras usadas nas suas e em outras famílias. A falta de modelos competentes leva à aceitação das práticas recebidas de seus pais como "normais". Portanto, estas pessoas não possuem uma visão de que punir fisicamente uma criança seja uma violência na relação paisfilhos, porque este é compreendido como um comportamento natural, e o ato de "bater" é uma forma disciplinar difundida (Kashani \& Allan, 1998; Simons e cols., 1991).

Simons, Whitbeck, Conger e Chyi-In (1991) identificaram algumas possibilidades da transmissão intergeracional desta parentalidade severa. Pais que foram expostos a altos níveis de disciplina coercitiva na infância podem desenvolver uma filosofia de prática educativa que favorece a severidade e a disciplina física, justificando sua maneira de criar ou educar a criança. Por outro lado, esta forma de exercer a parentalidade pode resultar na aprendizagem de uma série de práticas disciplinares agressivas, que passarão a ser utilizadas no futuro. A personalidade hostil e agressiva também contribui para tal, uma vez que os pais tendem a utilizar comportamentos agressivos para com as pessoas em geral, incluindo os próprios filhos. Pais que acreditam na legitimidade da disciplina severa ou que têm personalidades hostis apresentam maior probabilidade de utilizar a disciplina física em sua prática disciplinar. Da mesma forma, pais que receberam educação severa em suas infâncias têm maior probabilidade de acreditar na disciplina corporal. Tais hipóteses, no entanto, não são mutuamente excludentes.

Cabe ressaltar, contudo, que o ciclo de violência dentro da família pode ser rompido pela existência de fatores mediadores, como a rede de apoio social, a coesão familiar e a resiliência infantil e familiar (Bolger, Thomas \& Eckenrode, 1997; Cecconello, 2003; Kashani \& Allan, 1998). A capacidade das pessoas ou do sistema familiar de romper com a situação de violência e superar o evento revela esta condição de resiliência. Alguns fatores de proteção contribuem para que o ciclo de abuso seja interrompido. Egeland, Jacobvitz e Sroufe (1988) identificaram, por exemplo, que mães maltratadas em suas infâncias superaram esta condição, na presença de um adulto não-abusador que tenha lhe fornecido apoio durante a sua infância; na manutenção de um relacionamento estável com um companheiro na vida adulta que forneça apoio e bem-estar emocional; e na participação em alguma forma de psicoterapia durante algum tempo em sua vida. Estes fatores contribuíram para que estas mães estabelecessem relacionamentos saudáveis na vida adulta, protegendo seus filhos da repetição do ciclo de violência. 
Cecconello (2003) observou o rompimento do ciclo de violência em famílias cujos pais, na infância, foram submetidos a altos níveis de abuso e maus tratos. Os fatores que contribuíram para a interrupção deste ciclo foram: a manutenção de um relacionamento amoroso estável, que forneceu apoio e bem-estar emocional aos pais; a participação em psicoterapia e em grupos de auto-ajuda; e, a rede de apoio social estabelecida com pessoas significativas e com os recursos disponíveis no mesossistema, como o centro de saúde, a igreja e o próprio trabalho. Estes fatores propiciaram o estabelecimento de harmonia no ambiente familiar, contribuindo para que as relações entre pais e filhos fossem permeadas por afeto, reciprocidade e equilíbrio de poder, favorecendo, assim, a resiliência familiar.

De Antoni e Koller (2000) realizaram um levantamento de indicadores de proteção contra a violência, a partir da visão de adolescentes maltratadas. Estas adolescentes citaram como fatores que incrementam a resiliência familiar a presença da coesão neste microssistema, que permite aos membros se sentirem pertencentes ao grupo, ao compartilharem atividades, fornecerem apoio emocional, estabelecerem diálogo, ou quando os pais exercem práticas disciplinares restritivas e não punitivas, usando a orientação e a educação.

Diante da presença de fatores de risco e da escassez de fatores de proteção, o abuso físico pode levar a conseqüências diversas. Os mais graves são o óbito da vítima, principalmente nos casos de traumatismo cerebral, ou danos irreversíveis, como paralisias, deficiência visual ou prejuízo da capacidade cognitiva (Wharton, Rosenberg, Sheridan \& Ryan, 2000). Estão também presentes os efeitos do abuso emocional ou psicológico que acompanham o abuso físico. A necessidade básica de segurança das crianças para com seus pais é tolhida, e estas crianças podem apresentar baixa auto-estima, incapacidade para fazer amigos e problemas de comportamento. Crianças expostas a pais abusivos ou severos correm risco em seu desenvolvimento, pois tais comportamentos por parte dos pais podem desencadear conflitos com a lei, psicopatia, fracasso acadêmico, dificuldades com colegas e abuso de substâncias (Simons, Whitbeck, Conger \& Chyi-In, 1991).

Como é possível observar, as conseqüências do abuso físico para a criança e o adolescente são graves. Da mesma forma, os fatores que contribuem para a sua incidência são múltiplos, incluindo desde aqueles que operam nas esferas pessoal e familiar, em nível microssistêmico, até aqueles operando nos níveis meso, exo e macrossistêmicos. Na esfera familiar, a utilização indiscriminada da disciplina coercitiva e a crença nos valores autoritários parecem ser fatores de risco potenciais para desencadear o abuso físico. Por outro lado, nas esferas do exo e macrossistemas, o desemprego, a pobreza e a violência contribuem para que as famílias não tenham acesso a recursos básicos, como saúde, educação e trabalho, limitando suas possibilidades de estabelecimento de redes de apoio no mesossistema, levando, assim, ao seu isolamento e, conseqüentemente, ao abuso intrafamiliar.

Garbarino e Barry (1997) afirmam que o isolamento social das famílias é o preço pago pela sua privacidade em relação à sociedade. Ressaltam, no entanto, que a parentalidade, embora seja um papel exercido no microssistema familiar, não deixa de ser uma função social, pois os pais ou cuidadores necessitam de informações sobre o desenvolvimento infantil e adolescente e sobre práticas educativas. A privação das famílias, em relação aos serviços que poderiam desempenhar este papel de orientação, contribui para que eventuais distorções nas funções parentais dificilmente cheguem ao conhecimento público. Conforme ressalta Rosário (1999), ainda persiste a concepção cultural de que as situações ocorridas em ambiente privado não dizem respeito aos que não participam diretamente daquelas relações. No entanto, como muitos casos de abuso ocorrem em nível familiar, a responsabilidade pública sobre a saúde física e mental destas famílias precisa ser reconhecida, caso contrário, a sociedade estará condenando muitas crianças e adolescentes a serem violentados (Cecconello, 2003). Deste modo, a importância das redes de apoio social para a prevenção de abuso e maus tratos na família é fundamental.

É fundamental para a prevenção do abuso intrafamiliar estruturar uma rede de apoio social, através de serviços especializados que possam orientar as famílias sobre práticas educativas e fornecer informações sobre o desenvolvimento infantil e adolescente. Esta tarefa pode ser realizada dentro das escolas ou nos postos de saúde. Da mesma forma, uma estrutura para receber e encaminhar eficientemente as denúncias se constitui em um recurso importante, como a proposta realizada pelo ECA, através dos Conselhos Tutelares.

No entanto, é imprescindível que seja dado apoio às famílias. Ser vítima de abuso físico (principalmente a criança) transcende ao dano corporal e pode estar expresso psicologicamente no papel de ator (o abusador, freqüentemente, os pais) e no da testemunha (os demais integrantes da família), exigindo que a todos eles seja propiciado algum tipo 
de encaminhamento e atendimento. $\mathrm{O}$ bem-estar e o "tratamento" destas pessoas reflete-se em uma dimensão de saúde pública, porque o abuso intrafamiliar assume, atualmente, dimensões de um problema desta ordem. A interface das pessoas e do ambiente social do qual a família faz parte está relacionado com a percepção de seu mundo social. $\mathrm{O}$ apoio social e afetivo oferecido para a superação da condição de família abusiva reorienta as estratégias e as competências desta para o estabelecimento de novos vínculos e para a obtenção de recursos que o ambiente lhe oferece, como proteção e força (Brito \& Koller, 1999). Ao proporcionar tais possibilidades e recursos, a sociedade estará fortalecendo a família como um sistema social, contribuindo para a interrupção do ciclo de violência, e promovendo, assim, a resiliência.

\section{REFERÊNCIAS}

Alvarenga, P. (2000). Práticas educativas maternas e problemas de comportamento na infância. Dissertação de Mestrado, Universidade Federal do Rio Grande do Sul, Porto Alegre.

Bandura, A. (1979). Modificação do comportamento. Rio de Janeiro: Interamericana.

Baumrind, D. (1966). Effects of authoritative parental control on child behavior. Child Development, 37, 887-907.

Baumrind, D. (1971). Current patterns of parental authority. Developmental Psychology Monograph, 4 (1, Pt.2).

Baumrind, D. (1991). Effective parenting during the early adolescent transition. In P. A. Cowan \& M. Hetherington (Orgs.), Family transitions (pp. 111-163). New Jersey: Lawrence Erlbaum.

Baumrind, D. (1997). The discipline encounter: contemporary issues. Aggression and Violent Behavior, 2, 321-335.

Belsky, J. (1980). Child maltreatment: an ecological integration. American Psychologist, 35, 320-335.

Bolger, K.; Thomas, M. \& Eckenrode, J. (1997). Disturbances in relationships. In J. Garbarino \& J. Eckenrode (Orgs.), Understanding abusive families: ecological approach to theory and practice (pp. 86-98). San Francisco: Jossey-Bass.

Brito, R. C. \& Koller, S. H. (1999). Redes de apoio social e afetivo e desenvolvimento. Em A. M. A. Carvalho (Org.), $O$ mundo social da criança: natureza e cultura em ação (pp. 115-130). São Paulo: Casa do Psicólogo.

Bronfenbrenner, U. (1996). A ecologia do desenvolvimento humano: experimentos naturais e planejados. Porto Alegre: Artes Médicas (Original publicado em 1979).

Cecconello, A. M. (2003). Resiliência e vulnerabilidade em famílias em situação de risco. Tese de Doutorado, Universidade Federal do Rio Grande do Sul, Porto Alegre.

Coohey, C. (2000). The role of friends, in-laws, and other kin in father-perpetrated child physical. Child Welfare, 79(4), $373-402$.
Crouch, J., Milner, J. S. \& Thomsen, C. (2001). Childhood physical abuse, early social support, and risk for maltreatment: current social support as a mediator of risk for child physical abuse. Child Abuse and Neglect, 25(1), 93107.

Darling, N. \& Steinberg, L. (1993). Parenting style as a context: an integrative model. Psychological Bulletin, 113, 487-496.

De Antoni, C. (2000). Vulnerabilidade e resiliência familiar na visão de adolescentes maltratadas. Dissertação de Mestrado. Universidade Federal do Rio Grande do Sul. Porto Alegre.

De Antoni, C. \& Koller, S. H. (2000). Vulnerabilidade e resiliência familiar: um estudo com adolescentes que sofreram maus tratos intrafamiliares. Psico, 31(1), 39-66.

De Antoni, C., Mesquita, J. \& Koller, S. H. (1998). Perfil de meninas maltratadas: levantamento de dados em uma Casa de Passagem [Resumo]. Em Sociedade Brasileira de Psicologia do Desenvolvimento (Org.), Anais do II Congresso Psicologia do Desenvolvimento (p.46). Gramado, RS: SBPD.

De Antoni, C.; Medeiros, F.; Hoppe, M. W. \& Koller, S. H. (1999). Uma família em situação de risco: resiliência e vulnerabilidade. Interfaces: Revista de Psicologia, 2, 81-85.

Dopke, C. (1999). Stress and parenting behavior in high- and low-risk for child physical abuse mothers. The Sciences and Engineering, 59, 5077-86.

Egeland, B., Jacobvitz, D. \& Sroufe, L. A . (1988). Breaking the cycle of abuse: relationships predictors. Child Development, 59, 1080-1088.

Estatuto da Criança e do Adolescente. (1990). Lei n ${ }^{\circ} .069$, de 13-07-1990. São Paulo: Cortez.

Farinatti, F. A., Biazus, D. B. \& Leite, M. B. (1993). Pediatria social: a criança maltratada. São Paulo: Medsi.

Garbarino, J. \& Barry, F. (1997). The community context of child abuse and neglect. Em J. Garbarino \& J. Eckenrode (Orgs.), Understanding abusive families: ecological approach to theory and practice (pp. 56-85). San Francisco: Jossey-Bass.

Garbarino, J. \& Eckenrode, J. (1997). Understanding abusive families: ecological approach to theory and practice. San Francisco: Jossey-Bass.

Glasgow, K. L., Dornsbusch, S. M., Troyer, L, Steinberg, L. \& Ritter, P. L. (1997). Parenting styles, adolescentes attibutions, and educational outcomes in nine heterogeneous high schools. Child Development, 68, 507-529.

Grusec, J. E. \& Lytton, H. (1988). Social development: history, theory and research. New York, Springer-Verlag.

Hart, C. H., Ladd, G. W. \& Burleson, B. R. (1990). Children's expectations of the outcomes of social strategies: relations with sociometric status and maternal disciplinary styles. Child Development, 61, 127-137.

Hart, C. H., Nelson, D. A., Robinson, C. C., Olsen, S. F., \& McNeilly-Choque, M. K. (1998). Overt and relational aggression in Russian nursery-school-age children: parenting styles and marital linkages. Developmental Psychology, 34, 687-697.

Hoffman, M. L. (1960). Power assertion by the parent and its impact on the child. Child Development, 31, 129-143. 
Hoffman, M. L. (1975). Moral, internalization, parental power, and the nature of parent-child interaction. Developmental Psychology, 11, 228-239.

Kashani, J. H. \& Allan, W. D. (1998). The impact of family violence on children and adolescents. Thousand Oaks, Ca: Sage.

Kristensen, C. H., Oliveira, M. S. \& Flores, R. Z. (1999). Violência contra a criança e adolescentes na grande porto alegre. Parte B: Pode piorar? Em AMENCAR (Org.), Violência doméstica (pp.104-117). Brasília: UNICEF.

Koller, S. H. (1999). Violência doméstica: uma visão ecológica. Em AMENCAR (Org.), Violência doméstica (pp.32-42). Brasília: UNICEF.

Lamborn, S. D., Mounts, N. S., Steinberg, L. \& Dornbusch, S. M. (1991). Patterns of competence and adjustment among adolescents from authoritative, authoritarian, indulgent, and neglectful families. Child Development, 62, 1049-1065.

Maccoby, E. \& Martin, J. (1983). Socialization in the context of the family: parent-child interaction. Em P. H. Mussen (Org. Série) \& E. M. Hetherington (Org. Vol.), Handbook of child psychology: Vol. 4. Socialization, personality, and social development ( $4^{\mathrm{a}} \mathrm{ed}$.)( pp. 1-101). New York: Wiley.

Oates, R. K., Ryan, M. \& Booth, S. M. (2000). Child physical abuse. In R. Ammerman e M. Hersen (Orgs.), Cases studies in family violence (pp. 133-176). New York: Plenum.

Pacheco, J. T. B., Texeira, M. A. P. \& Gomes, W. B. (1999). Estilos parentais e desenvolvimento de habilidades sociais na adolescência. Psicologia: Teoria e Pesquisa, 15, 117126.

Patterson, G. R. \& Capaldi, D. M. (1991). Antisocial parents: unskilled and vulnerable. Em P. A. Cowan \& M. Hetherington (Orgs.), Family Transitions (pp. 195-218). New Jersey: Lawrence Erlbaum.

Pelcovitz, D., Kaplan, S., Ellenberg, A., Labruna, V., Salzinger, S., Mandel, F. \& Weiner, M. (2000). Adolescent physical abuse: age at time of abuse and adolescent perception of family functioning. Journal of Family Violence, 15(4), 375-389.

Pires, J. (1999). Violência na infância: Aspectos clínicos. AMENCAR (Org.), Violência doméstica (pp. 61-70). Brasília: UNICEF.

Rosário, M. (1999). Políticas públicas voltadas para a proteção de crianças e adolescentes vítimas de violência. Em AMENCAR (Org.), Violência doméstica (pp.12-17). Brasília: UNICEF.
Septimus-Berger, A. (1999). Adolescent physical abuse: predictive factors. The Sciences and Engineering, 59, 3713-35.

Simons, R. L. \& Johnson, C. (1996). The impact of marital and social network support on quality of parenting. In G. R. Pierce, B. R. Sarason \& I. G. Sarason (Orgs.), Handbook of social support and the family (pp. 269-287). New York, NY: Plenum Press.

Simons, R. L., Lorenz, F. O., Conger, R. D. \& Wu, C. (1992). Support from spouse as mediator and moderator of the disruptive influence of economic strain on parenting. Child Development, 63, 1282-1301.

Simons, R., Whitbeck, L. B., Conger, R. D. \& Chyi-In, W. (1991). Intergenerational transmission of harsh parenting. Developmental Psychology, 27(1), 159-171.

Steinberg, L., Catalano, R. \& Dooley, D. (1981). Economic antecedents of child abuse and neglect. Child Development, 52, 975-985.

Steinberg, L., Lamborn, S. D., Darling, N., Mounts, N. S. \& Dornbusch, S. M. (1994). Over-time changes in adjustment and competence among adolescents from authoritative, authoritarian, indulgent, and neglectful families. Child Development, 65,_754-770.

Steinberg, L., Mounts, N. S, Lamborn, S. D. \& Dornbusch, S. M. (1991). Authoritative parenting and adolescent adjustment across varied ecological niches. Journal of Research on Adolescence, 1, 19-36.

Wharton, R., Rosenberg, S., Sheridan, R. L. \& Ryan, D. (2000). Long-term medical consequences of physical abuse. Em R. M. Reece (Org.). Treatment of child abuse: common ground for mental health, medical, and legal practitioners (pp. 117-134). Baltimore, MD: The Johns Hopkins University Press.

Wilson, S. R. \& Whipple, E. (2001). Attributions and regulative communication by parents participating in a community-based child physical abuse prevention program. Em V. Manusov \& J. H. Harvey (Orgs.), Attribution, communication behavior, and close relationships. Advances in personal relations (pp. 227-247). New York, NY, US: Cambridge University Press.

Recebido em 04/02/2003

Revisado em 17/04/2003

Aceito em 30/06/2003 